\title{
Reproduction of Symbolic Representation in Translating Chinese Classical Poetry
}

\author{
Qingjun MA \\ Tianjin Maritime College, Tianjin, China
}

\begin{abstract}
In Chinese Classical Poetry, there are so many Chinese terms which carry symbolic meaning. It is a hard nut for a translator to crack to successfully reproduce their cultural symbol in the Western Culture. Literal translation adding notes and building a bridge between the symbolic representation and the source are good means in reproducing symbolic representation of Chinese Classical Poetry.

KEYWORDS: Symbolic Representation; Chinese Classical Poetry (CCP); Literal Translation ; Cultural Misunderstanding
\end{abstract}

\section{INTRODUCTION}

Symbol, as a writing technique, refers to writing some images, objects, etc. that suggest or refer to something else. So it often results in double-layer artistic conception. In CCP, for some reason, the poets often hide the subtle feelings in the lines they write, which are not easy to find, but actually they can be discovered by readers after they read the lines carefully. The readers will have a delightful surprise when they find something hidden in the poem. The poems successfully employing symbol, like perfect handcrafts, often make the people indulge in them, that is, the poems are so readable that the readers find it not easy to tear themselves away. As a matter of fact, symbol is made up of the source and the symbolic representation. The two have to perfectly relate to each other. If not, the readers will put it aside and never read it again. Usually, the following means can well reproduce the beauty of the poems that carry symbol.

\section{LITERAL TRANSLATION ADDING NOTES}

In translation of the poems that contain deep artistic conception, the source containing the original idea should not be directly figured out, but symbolic body must be clearly depicted. In the circumstances, the translator should give it a literal translation. Otherwise, the readers will not get the same aesthetic pleasure from the target poem as the original. Virtually, the kind of poems is difficult for the readers to understand, so it is necessary to put some notes to the target poem, expressing the age in which the poet lives and the personal circumstances, so that the target readers can understand it more easily.

For example:

\section{近试上张籍水部 朱庆余 \\ 洞房昨夜停红烛, 待晓堂前拜舅姑。 妆罢低声问夫婿：画眉深浅入时无？}

In the Tang Dynasty, there was a custom of a candidate for the imperial examination presenting his own masterpieces to literary scholars or high-ranking government officials, expecting their recommendation. Zhang $\mathrm{Ji}$, a famous poet in Tang Dynasty, would like to take up the promising young. The poet, Zhu Qingyu, had presented his own masterpieces to Zhang, and had got Zhang's high praise, but he still felt nervous, so he wrote the poem. In the poem, Zhu contrasts himself to a bride, Zhang Ji the bridegroom, and the Claims Examiner parentsin-law, expecting Zhang's reply. The first two lines, “洞房昨夜停红烛, 待晓堂前拜舅姑。”, seem that they only express the folkways, in which, actually, the tension and the hurry of the bride are hidden. In order not to delay paying a formal visit to parents-in-law the next morning, the bride keeps the candles burning all the night, during which time she

Ma Qingjun(1973 - ), Associate professor of Tianjin Maritime College from Shandong Province of China. Research Area: Translation Theory and Practice, English Education, etc.

Address: 8 Yashen Road, Tianjin Haihe Education Park. The Foreign Studies Department, Tianjin Maritime College 
wakes up several times, only to find it is still dark outside. Since she fails to fall into sleep, she simply sits at the dressing table for a makeover. After finishing the makeover, it is still too early. She has no choice but to lie down for a rest, only to find it is high time she went to kowtow to her parents-in-law. So she hurries to do a makeover again. The two lines, “妆罢低声问夫婿：画眉深浅入时无?”, seem a casual question, but actually they mean much. As a symbolic representation, the poem is perfect. That is to say, the surface meaning is perfectly revealed. Meanwhile, the deep meaning is perfectly hidden in it. As a matter of fact, the poet, Zhu Qingyu, wants to express his own feeling through the poem. In his opinion, the imperial examination is so important to him. If he succeeds, he will get a plain sailing in the official seas. Otherwise, he will suffer a lot of hardships in the future. The poet's symbol is so perfect that Zhang Ji gives him a clear reply using the same technique.

越女新妆出镜心，自知明艳更沉吟。

齐纨未足时人贵, 一曲菱歌敌万金。 （张籍《酬朱庆余》）

The well-dressed Yue girl appears in Jinghu Lake's heart,

Not very confident though fresh beauty she has got.

The other girls in Qi Silk can not surpass her in grace;

One water caltrop picking song is worth gold of ounces.

\section{(Tr. the author)}

The reply implies that there is no need for Zhu to worry about the coming imperial examination. In translation, the literal translation of the symbolic representation is not enough as it is difficult for the target readers to understand the original poet's intention, so it is necessary to reveal the source. In the circumstances, adding proper notes is a way out. That is, the translator provides the circumstances of the imperial examination in Tang Dynasty, the relationship between Zhu Qingyu and Zhang Ji, and the reason for writing the poem in the notes. Here is the target poem.

Last night red candles burned low in the bridal room,

At dawn she'll kowtow to new parents with the groom,

She whispers to him after touching up her face:

"Have I painted my brows with fashionable grace?"

\section{(Tr. Xu Yuanzhong)}

In the target poem, the translator reproduces the symbolic representation - the surface meaning. The target readers will understand the internal meaning of the poem, that is, the poet's intention, on reading the notes together with it.

\section{BUILDING A BRIDGE BETWEEN THE SYMBOLIC REPRESENTATION AND THE SOURCE}

According to German philosopher Cassirer, symbol, as a technique, is a kind of relationship built between cognitive symbols and some meanings that appears in human's consciousness. The so-called "perceptual phenomenon" refers to poetry images, that is, the language describing images. The symbolic representation and the source have close relationship on the sly, but in public, they have nothing to do with each other. The poet let them talk love on the sly, which is very mysterious and beautiful. But some readers do not know the fact, mistaking them for strangers to each other. Is there a thread to join the two? According to Professor $\mathrm{Gu}$ Zhengyang, sometimes there is one. The thread drops a hint, but not offers overtone, which can avoid a lengthy and tedious explanation in the notes, making the target readers open up the wings of imagination and enjoy the beauty of the poem.

Example 1:

\section{七步诗}

曹豆䐈
然豆其, 豆在釜中泣。

Cao Pi and Cao Zhi were whole brothers in the Three Kingdoms Period. When their father, Cao Cao was alive, the two used every means, open and secret, direct and indirect for the Crown Prince. Cao Zhi, loved by Cao Cao for his talent and beautiful poems, failed in the end for his heavy bookishness. After Cao Pi came into power, Cao Zhi was still a grumbler, not submitting to him. So Cao Pi tried to seek proper opportunity to get him of Cao Zhi. Once, Cao Pi ordered Cao Zhi to write down a poem in seven paces. If not, Cao Zhi would be killed at once. Cao Zhi had no choice but to obey the order from his own elder brother. Having sharp-witted response, Cao Zhi wrote down the poem appealing to all people. It is very common for the people to use"豆 萁”, that is, beanstalks, to boil the hard bean to soft state. But some philosophy is hidden in here-the very fratricidal action, which does not easily occur to the common people. The technique of personification is used in “豆在釜中泣”。The poet, Cao Zhi, imagined the sound of the beans in the pot with burning beanstalk under to be the sound of cry. In fact, beans never cry. It is he who suffers that is crying. Why are the beans crying? What are the beans crying for? “本身同根生”. The poet, Cao Zhi, revealed the reason directly. The fact that the beans 
and the beanstalk are born from the same root implies that the two are the same mother's sons. The beanstalk boils the beans, implies that the elder brother will kill the younger, which is too inhuman. “相煎何太急”, boiling is too common as a means to cook food. But it implies that it is the younger brother who will be boiled. Surely it is terrifying. A kind of sad beauty is hidden in the poem. “何” served as a foil and"太"as reinforcement, the line is full of resentment and sad helplessness, making Cao Pi feel ashamed and difficult to carry out the plot. With time going on, the poem, simplified as “煮豆 燃萁，同是根生”, becomes more and more popular. The target readers will find it interesting on reading the literal translation of the poem and perhaps they will have some comprehension, regarding it as a fight among clansmen. But they seldom come to the conclusion that it is a fratricidal action. If some clues are to be put in the target poem, the target readers will better understand the poet of the original. Here is the target poem.

A kettle had beans inside,

And stalks of the beans made a fire;

When the beans to the brother-stalks cried,

"We sprang from one root, why such fire?" (Tr. Gu Zhengyang)

The translator puts "brother", a modifier used as restrictive attributive before "stalks", which well reproduces the original poem. On reading the line, they will open up the wings of imagination, bringing the royal fratricidal fights in the history in the minds. Though the stories are different, the symbolic meaning and the sad beauty that they get are almost the same.

The author thinks that "brother-stalks" exactly reproduces Cao Zhi's feeling then. It's almost impossible for anyone else to find a better word to replace it.

Example 2:

滴不尽乡思血泪抛红豆, 开不完春柳春花满画 楼。(The Story of the Stone, Chapter 28)

Still weeping tears of blood about our separation: Little red love-beans of my desolation. Still blooming flowers I see outside my window growing. (Tr. David Hawkes)

Red bean, also called love bean in Chinese, stands for lovesickness. Wang Wei, a famous poet in the Tang Dynasty once wrote a poem called Love Seeds

$$
\begin{aligned}
& \text { 相思 } \\
& \text { 王维 } \\
& \text { 红豆生南国, 春来发几枝。 } \\
& \text { 愿君多采撷, 此物最相思。 }
\end{aligned}
$$

Love Seeds

Red berries grow in southern land.

How many load in spring the trees?
Gather them till full is your hand;

They would receive fond memories. (Tr. Xu Yuanzhong)

The poem is very popular with the Chinese people. In the English version, Prof. Xu Yuanzhong employs "red berries" to translate “红豆 (red bean)", successfully avoiding its ambiguity. If "red bean" is employed to translate "红豆 (red-bean)", cultural misunderstanding may occur in the western readers. As a matter of fact, red bean has got a derogatory symbol in the Western Culture. In the Bible, the eldest son Esau sold his birthright to his twin brother Jacob just for a bowl of red-bean stew. As a result, "red bean" got a cultural symbol for foolishness, which is much different from that of the Chinese Culture. In translating Hongloumeng, to avoid misunderstanding, Prof. David Hawkes employed "red love-beans" to translate “红豆 (redbean)", which was a great creation according to the author of the thesis. As it not only retains the color of the Chinese term “红豆 (red-bean)", but also avoids the ambiguity of red bean in the western readers. Actually, Prof. David Hawkes successfully built a bridge the symbolic representation and the source.

\section{CONCLUSION}

Reproduction of symbolic representation in another language is a hard nut for a translator to crack. Despite the fact, so many Chinese classical Poems which carry symbolic representation have been translated into English. Literal translation adding notes and building a bridge between the symbolic representation and the source are good means in reproducing symbolic representation of Chinese Classical Poetry.

\section{REFERENCES}

[1] Gu Zheng-yang, New Aesthetic Approach to English Translation of Ancient Chinese Poetry. Shanghai: Shanghai University Press, 2006.

[2] Xu Yuan-zhong, etc. 300 Tang Poems, A New Translation. Beijing: China Translation \& Publishing Corporation, 1997.

[3] David Hawkes, The Story of the Stone. Penguin Books Limited London, 1981. 